\author{
B.I. Kuznetsov, T.B. Nikitina, I.V. Bovdui
}

\title{
HIGH VOLTAGE POWER LINES MAGNETIC FIELD SYSTEM OF ACTIVE SHIELDING WITH COMPENSATION COIL DIFFERENT SPATIAL ARRANGEMENT
}

\begin{abstract}
Aim. The synthesis of single-circuit system of active shielding of magnetic field, generated by group of high voltage power lines, with different spatial arrangement of shielding coil. Methodology. The synthesis is based on the decision of a multi-criteria stochastic game, in which the vector payoff is calculated on the basis of the Maxwell equations solutions in the quasi-stationary approximation. The game decision is based on the stochastic multiagent optimization algorithms by multiswarm particles. The initial parameters for the synthesis of active shielding system are the location of the high voltage power lines with respect to the shielding space, geometry and number of shielding coils, operating currents, as well as the size of the shielding space and normative value magnetic flux density, which should be achieved as a result of shielding. The objective of the synthesis of the active shielding system is to determine their number, configuration, spatial arrangement, wiring diagrams and shielding coils currents, setting algorithm of the control systems as well as the resulting of the magnetic flux density value at the points of the shielding space. Results. Three variant of single-circuit robust system of active shielding with different spatial arrangement of shielding coil synthesis results for reduction of a magnetic field generated by group of high voltage power lines is given. The possibility of a significant reduction in the level of magnetic flux density of the magnetic field source within and reducing the sensitivity of the system to uncertainty of the plant parameters is given. Originality. For the first time carried out the synthesis, theoretical and experimental research of the robust system of active shielding of magnetic field generated by group of high voltage power lines with different spatial arrangement of compensation coil. Practical value. Practical recommendations from the point of view of the practical implementation on reasonable choice of the spatial arrangement of shielding coil of robust singlecircuit system of active shielding of the magnetic field generated by the group of high voltage power lines is given. References 49 , figures 9.
\end{abstract}

Key words: high voltage power lines, power frequency magnetic field, robust system of active shielding, multi-criteria stochastic game.

Цель. Синтез одноконтурной робастной системы активного экранирования магнитного поля, создаваемого группой высоковольтных линий электропередачи, с различным пространственным расположением экранируюцей обмотки. Методология. Синтез основан на решении многокритериальной стохастической игры, в которой векторный выигрыш вычисляется на основании решений уравнений Максвелла в квазистационарном приближении. Решение игры находится на основе алгоритмов стохастической мультиагентной оптимизации мультироем частиц. Исходными параметрами для синтеза системы активного экранирования являются расположсене высоковольтных линий электропередачи по отночению к зацищаемому пространству, геометрические размеры, количество проводов и рабочие токи линии электропередачи, а такэе размеры экранируемого пространства и нормативное значение индукции магнитного поля, которое долюкно быть достигнуто в результате экранирования. Целью синтеза системы активного экранирования является определение количества, конфигурации, пространственного расположения, схем электропитания и токов экранирующей обмоток, алгоритма работы системы управления, а также результирующего значения индукционного магнитного поля в точках экранируемого пространства. Результаты. Приводятся результаты трех вариантов синтеза одноконтурной робастной системы активного экранирования с различным пространственным расположением экранирующей обмотки для уменьщения магнитного поля, создаваемого группой высоковольтных линий электропередачи. Показана возможность существенного снижения уровня индукции исходного магнитного поля внутри экранируемого пространства и снижения чувствительности системы к неопределенности параметров системы. Оригинальность. Виервые проведены синтез, теоретические и экспериментальные исследования одноконтурной робастной системы активного экранирования магнитного поля, создаваемых группой высоковольтными линиями электропередач в области экранируемого пространства, с различным пространственным расположением экранирующей обмотки. Практическая ценность. Приводятся практические рекомендации по обоснованному выбору с точки зрения практической реализации пространственного расположсения экранирующей обмотки одноконтурной робастной системы активного экранирования магнитного поля, создаваемого группой высоковольтных линий электропередач. Библ. 49, рис. 9.

Ключевые слова: высоковольтные линии электропередачи, магнитное поле промышленной частоты, робастная система активного экранирования, многокритериальная стохастическая игра.

Introduction. Active contour shielding of power frequency magnetic field (MF) generated by high voltage power lines (HVPL) [1-10] is the most acceptable and economically feasible for ensuring the sanitary norms of Ukraine in the power frequency MF [11, 12].Ukraine's electricity networks are characterized by high density, and especially near high-voltage power substations. There is usually a group of overhead HVPL, in the immediate vicinity of which can be located residential buildings. In this case, the main uncertainty in the synthesis of systems of active shielding (SAS) is the variation of the currents of different power lines, which leads not only to a change in the level of magnetic flux density, but also to a change in the position of the space-time characteristics (STC) of the MF in the shielding zone.

Most of the double-circuit HVPL, and groups of HVPL generate MF, which has a slight polarization. The STC of such MF has the form of a strongly elongated ellipse [5] and, therefore, active shielding of such MF is possible with the use of only single shielding coil (SC). Such single-circuit SAS with single SC are most widely used in world practice [2-6]. Naturally, that the realization of $\mathrm{SC}$ can be performed by various ways. 
The methods of synthesis of SAS for MF, generate by HVPL, was developed in [13-24]. The initial data for the synthesis of the system is the parameters of the transmission lines (working currents, geometry and number of wires, location of the transmission lines relative to the protected space) and the dimensions of the protected space and the standard value of the magnetic flux density, which should be achieved as a result of shielding. In the process of synthesis, it is necessary to determine the parameters of the SC (their number, configuration, spatial arrangement, connection diagram), currents and the resulting magnetic flux density.

The goal of this work is the synthesis of singlecircuit systems of active shielding of power frequency magnetic field generated by group of high voltage power lines with different spatial arrangement of the single shielding coil.

Problem statement. In the synthesis of the ASS, the mathematical model of the original $\mathrm{MF}$ is known inaccurately [25]. In particular, currents in conductors that have daily, weekly, seasonal variations are approximately known which leads to a change of the STC position of the original $\mathrm{MF}$, generated by the power lines. The geometric dimensions of the $\mathrm{SC}$, the parameters of the regulators, etc. are not accurately realized. Therefore, we introduce a vector of uncertainty of the system parameters from their nominal values $\delta$ used in the synthesis of the system. The problem of synthesizing a robust SAS is reduced to the determination of such a vector of spatial arrangement and geometric sizes of compensated windings, as well as parameters of the regulator $X$ and the uncertainty parameters vector $\delta$, at which the maximum value of the magnetic flux density at selected points $P_{j}$ of the considered space $P$ assumes a minimum value for thevector of spatial arrangement and geometric sizes of compensated windings, as well as parameters of the regulator $X$ but the maximum value for the uncertainty parameters vector $\delta$, so that

$$
X^{*}=\arg \min _{X \in \boldsymbol{X}} \max _{\delta \in \Delta} \max _{P_{j} \in \boldsymbol{P}} B\left(X, \delta, P_{j}\right) .
$$

This technique corresponds to the standard approach to the synthesis of robust systems for the worst-case [25], when the uncertainty parameters vector $\delta$ lead to the greatest deterioration in the compensation of the initial MF created by HVPL. The problem (1) can be formulated in the form of the following multi-criteria game [16] with vector payoff

$$
B(X, \delta)=\left[B\left(X, \delta, P_{1}\right), B\left(X, \delta, P_{2}\right) \ldots B\left(X, \delta, P_{m}\right)\right]^{T},
$$

the components of which $B\left(X, \delta, P_{i}\right)$ are the magnetic flux density in the $m$ points $P_{i}$ of the space under consideration. In this case, of course, it is necessary to take into account the constraints on the control vector and the state variables of the system, the uncertainty parameters vector in the form of a vector inequality

$$
G(X, \delta) \leq G_{\max } .
$$

In the multi-criteria game (2), the first player is the vector of spatial arrangement and geometric sizes of SC, as well as parameters of the regulator $X$ and its strategy is the minimization of the vector payoff (2), and the second player is a uncertainty parameters vector $\delta$ and the strategy of this player is maximization of the same vector payoff [25-27].

Note that the components of the vector payoff (2) are nonlinear functions of the vector of spatial arrangement and geometric sizes of SC, as well as parameters of the regulator $X$ and uncertainty parameters vector $\delta$ are calculated on the basis of the Maxwell equations solutions in the quasi-stationary approximation [28-36].

Solution algorithm. Consider the algorithm for finding the solution of the game. To find the solution of the multi-criterion game (9) from Pareto-optimal solutions taking into account the binary preference relations [37], we used an particle multi swarm optimization (PSO) algorithm [38, 39], in which the number of swarms are equal the number of components $m$ of the vector payoff (2).

In the standard particles swarm optimization algorithm the particle velocities change is carried out according to linear laws [37-47]. To increase the speed of finding a global solution, special nonlinear algorithms of stochastic multi-agent optimization recently proposed in [48], in which the motion of $i$ particle of $j$ swarm is described by the following expressions

$$
\begin{gathered}
v_{i j}(t+1)=w_{1 j} v_{i j}(t)+c_{1 j} r_{1 j}(t) * \ldots \\
\ldots * H\left(p_{1 \mathrm{ij}}(\mathrm{t})-\varepsilon_{1 i j}(t)\right)\left[y_{i j}(t)-\ldots\right. \\
\left.\ldots-x_{i j}(t)\right]+c_{2 j} r_{2 j}(t) H\left(p_{2 i j}(t)-\ldots\right. \\
\left.\ldots-\varepsilon_{2 i j}(t)\right)\left[y_{j}^{*}(t)-x_{i j}(t)\right] \\
u_{i j}(t+1)=w_{2 j} u_{i j}(t)+c_{3 j} r_{3 j}(t) H^{*} \ldots \\
\ldots *\left(p_{3 i j}(t)-\varepsilon_{3 i j}(t)\left[z_{i j}(t)-\delta_{i j}(t)\right]+\ldots\right. \\
\ldots+c_{4 j} r_{4 j}(t) H\left(p_{4 i j}(t)-\varepsilon_{4 i j}(t)\right) * \ldots \\
\ldots *\left[z_{j}^{*}(t)-\delta_{i j}(t)\right] \\
x_{i j}(t+1)=x_{i j}(t)+v_{i j}(t+1) ; \\
\delta_{i j}(t+1)=\delta_{i j}(t)+u_{i j}(t+1),
\end{gathered}
$$

where $x_{i j}(t), \delta_{i j}(t)$, and $v_{i j}(t), u_{i j}(t)$ are the position and velocity of $i$ particle of $j$ swarm.

Note that in connection with the fact that the vector game solutions (9) is represented in the form of strategies of two players $X$ - the vector of the parameters of the regulators and the $\delta$ - the uncertainty parameters vector, where it is necessary to minimize the vector payoff (9) along the regulators parameter vector $X$ and maximize the same vector payoff (9) with respect to the uncertainty parameters vector $\delta$. Therefore, each $i$ particles of $j$ swarm has two components of position $x_{i j}(t), \delta_{i j}(t)$ and two components of velocity $v_{i j}(t), u_{i j}(t)$ to find the two desired components of the regulators parameters vector $X$ and uncertainty parameters vector $\delta$.

In (4)-(6) $y_{i j}(t), z_{i j}(t)$ and $y_{j}{ }^{*}(t), z_{j}^{*}(t)-$ the best local and global positions of the $i$-th particle, found respectively by only one $i$-th particle and all the particles of $j$ swarm.

Moreover, the best local position $y_{i j}(t)$ and the global position $y_{j}{ }^{*}(t)$ of the $i$ particle of $j$ swarm are understood in the sense of the first player strategy $x_{i j}(t)$ for minimum of component $B\left(X, \delta, P_{i}\right)$ of the vector payoff (9). However, the best local position $z_{i j}(t)$ and the global 
position $z_{j}^{*}$ of the $i$ particle of $j$ swarm are understood in the sense of the second player strategy $\delta_{i j}(t)$ for maximum of the same component $B\left(X, \delta, P_{i}\right)$ of the vector payoff (2). This approach corresponds to the movement of particles along the gradient and antigradient when using deterministic game-solving algorithms.

Four independent random numbers $r_{1 j}(t), r_{2 j}(t), r_{3 j}(t)$, $r_{4 j}(t)$ are in the range of $[0,1]$, which determine the stochastic particle velocity components.

Positive constants $c_{1}, c_{2}$ determine the cognitive and social weights of the particle velocity components.

Note that this PSO algorithm is a fairly simple optimization algorithm. This algorithm does not require finding partial derivatives - a gradient vector, second order partial derivatives - a Hess matrix, a gradient projection matrix for constraints -Rosen matrix, an inversion of the Hess matrix, and so on. However, despite its simplicity, with the help of this algorithm it is possible to solve quite complex optimization problems in various fields. The success of the use of this algorithm, to a large extent, is determined by the justified choice of the tuning parameters of this algorithm. Let us consider in more detail the informed choice of the tuning parameters of this algorithm for solving the considered problem.

The peculiarity of the solution of this game is that the first player vector strategy components $x_{i j}(t)$ are the SC geometric dimensions, which measured in meters, and the open loop control regulators parameters - the phases of SC currents $i$, which measured in radians, SC ampere turns, which measured in ampere turns, and closed-loop control regulators gains, which measured in dimensionless quantities. Therefore, the values of these constants $c_{1 j}, c_{2 j}$ and $c_{3 j}, c_{4 j}$ are chosen taking into account the range of possible players strategies $X$ and $\delta$.

The peculiarity of the solution of this problem also is the presence of «ravines» and «edges» in the vector payoff (9). This is due, firstly, to the fact that the values of the components of the players' strategies $X$ and $\delta$ differ by more than an order of magnitude. Second, the change of some components of the players' strategies, in particular, the closed loops control regulators gains, leads to insignificant changes in the vector game payoff (2). Therefore, to improved the global solution finding speed with small increments changes in the payoff (2) for players' strategies $x_{i j}(t), \delta_{i j}(t)$ a nonlinear Cuckoo search algorithm of stochastic multi-agent optimization [48] used in (4) - (6).

The Heaviside function $H$ is used as a switching function of the motion of a particle, respectively, to the local $y_{i j}(t), z_{i j}(t)$ and global $y_{j}^{*}(t), z_{j}^{*}(t)$ optimum.

Switching parameters of the cognitive $p_{1 i j}, p_{3 i j}$ and social $p_{2 i j}, p_{4 i j}$ components of the particle velocity to the local and global optimum taken in the form of increments changes in the payoff (9) for players' strategies $x_{i j}(t), \delta_{i j}(t)$ when moving to local and global optimum respectively.

Random numbers $\varepsilon_{1 i j}(t), \quad \varepsilon_{2 i j}(t), \quad \varepsilon_{3 i j}(t)$ and $\varepsilon_{4 i j}(t)$ determine the switching parameters of the particle motion, respectively, to local and global optima. If $p_{1 i j}<\varepsilon_{1 i j}(t)$ and $p_{2 i j}<\varepsilon_{2 i j}(t)$, then the movement speed component $v_{i j}(t)$ of this $i$ particle of $j$ the swarm at the step $t$ does not change and the particle moves in the same direction as at the previous optimization step.

Similarly if $p_{3 i j}<\varepsilon_{3 i j}(t)$ and $p_{4 i j}<\varepsilon_{4 i j}(t)$, then the movement speed component $u_{i j}(t)$ of $i$ particle of $j$ the swarm at the step $t$ also does not change.

To improve the quality of the solution finding process, the inertia coefficients $w_{1 j}, w_{2 j}$ are used in the range of $(0.5-0.9)$.

As constraints (3) in this problem, first of all, we took into account the constraints on the SC spatial arrangement, which are first player vector strategy components $x_{i j}(t)$. These limitations are due to the technical possibilities of the SC implementation. In addition, the closed loops control regulators gains, which are also first player vector strategy components $x_{i j}(t)$. In addition, restrictions were set on the maximum particle velocities $v_{i j}(t), u_{i j}(t)$ based on the desired accuracy of obtaining the corresponding components of the vector game solution (2) as well as to improve the game solution convergence.

To find a global solution of the original multiobjective game (2) in the search for optimal solutions to local games, individual swarms exchange information among themselves. In this case, to calculate the velocity of the particles in one swarm, information on the global optimum obtained by the particles of the other swarm is used, which makes it possible to isolate all potential Pareto optimal solutions.

For this purpose, at each step $t$ of the movement of particle $i$, of swarm $j$ uses the binary preferences functions of local solutions obtained by all swarms. The solution $X_{j}^{*}(t)$ obtained in the course of solving the game $B\left(X(t), \delta(t), P_{j}\right)$ with the help of swarm $j$ is preferable to the solution $X_{k}{ }^{*}(t)$ obtained during optimization of the game $B\left(X(t), P_{k}\right)$ with the help of swarm $k$ if the condition

$$
\max _{i=1, m} B\left(P_{i}, X_{j}^{*}(t), \delta(t)\right)<\max _{i=1, m} B\left(P_{i}, \ldots X_{k}^{*}(t), \delta(t)\right)
$$

is satisfied.

In this case, as the global optimal solution $X_{k}^{*}(t)$ of swarm $k$, the global solution $X_{j}^{*}(t)$ obtained by the swarm $j$ is used, which is more preferable with respect to the global solution $X_{k}^{*}(t)$ obtained by swarm $k$ on the basis of the preference relation (7).

In fact with this approach the basic idea of the method of successive narrowing of the field of compromise problems is realized: from the initial set of possible solutions, based on information about the relative importance of local solutions, all Pareto-optimal solutions that can not be selected according to the available information on the relation pre-reverence. Removal is carried out until a globally optimal solution is obtained. As a result of applying this approach, no potentially optimal solution will be removed at each step of the contraction.

In conclusion, we note that the original multiobjective game (2) - (3), taking into account the algorithm for its solution (4) - (6), is a multi-criteria stochastic dynamic game, since it clearly has time and random search [27].

Computer simulation results. Consider the result of synthesis of robust SAS of MF generated by group of 
HVPL. This situation is typical for the outskirts of cities, where several power lines are suitable, as well as near power line substations. Figure 1 shows the location of a group of HVPL generating MF, the magnetic flux density of which must be reduced in the shielding zone. In the immediate vicinity of the shielding zone there are two double-circuit $110 \mathrm{k} V$ HVPL, a double-circuit $330 \mathrm{kV}$ HVPL and a single-circuit $330 \mathrm{k} V$ HVPL.

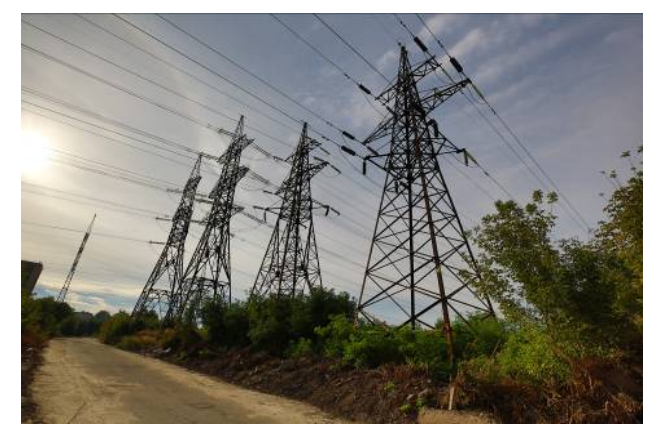

Fig. 1. Location of a group of high voltage power lines

For the synthesis of SAS, in addition to the geometric dimensions of the transmission lines and the shielding zone, the values of the currents in the bus of the all HVPL are necessary. To this, first, experimental studies of the level of the magnetic field both in the shielding zone and near the transmission lines were carried out. Based on the obtained experimental data, the problem of current identification in current conductors of the power line is solved, under which the sum of the squares of the errors of the measured and model - them magnetic flux density values at given points is minimized.

First, we will look the results of the SAS initial MF in a two-story cottage located at $20 \mathrm{~m}$ distance from the HVPL. On the basis of experimental research, it was found that in the shielding zone, the MF generated by group of HVPL has the STC of such MF is a strongly elongated ellipse and, consequently, the initial MF has a negligible polarization. Active screening of such MF is possible with the use of single SC. It should be noted that such systems have become most widespread in the world practice [2]. Based on the model of MF created by group of HVPL, the problem of synthesis of a robust SAS was solved. The SAS contains single $\mathrm{SC}$ which is square shape. The upper branch of SC is coordinates $(1.0,10.0)$, and the lower branch is coordinates $(10.0,1.3)$.

In Fig. 2, $a$ shows the isolines of the resultant magnetic flux density with the SAS is on. As can be seen from Fig. 2, $a$, the minimum magnetic flux density value in the shielding zone is $0.2 \mu \mathrm{T}$. The initial MF generated by the HVPL group in the shielding zone exceeds the level of $2.0 \mu \mathrm{T}$ and, therefore, the maximum shielding factor of the SAS is more than 10. When the active shielding system is on, as can be seen from Fig. 2, a, the magnetic flux density level in the residential space under consideration does not exceed $0.5 \mu \mathrm{T}$.

Figure $2, b$ shows the STC of MF, created by: group of HVPL (1); SC (2) and total MF with the SAS is on (3).

The STC of the initial MF is ellipse, which confirms the weak polarization of the initial MF. MF STC of SC is a straight line and, consequently, the SC generates unpolarized MF. Naturally, the initial MF with such STC can be effectively compensated for using a single-loop ASS with single SC. Wherein the big axis of the STS ellipse of the initial MF is compensated, so that the STS of the total MF with the SAS is on is an ellipse with an ellipse coefficient 0.8. The STC of the resultant MF is an ellipses of a significantly smaller area compared to the ellipse of the STC of the initial MF, which is due to the initial MF compensation with the help of the SAS.

When implementing the SAS, for mounting such a $\mathrm{SC}$ at a height of 10 meters, appropriate supports are necessary, which requires fairly large material costs.

Let us now consider the results of the synthesis of a MF SAS in a single-story building located at a distance of $7 \mathrm{~m}$ from HVPL. During SAS synthesis of different variants of the SC spatial arrangement were considered. Three variants of SC spatial arrangement were chosen which are the greatest interest from the point of view of the practical implementation of SC. Let us consider in more detail these three variants. In all these three variants $\mathrm{SC}$ are square shape. In the variant a) the upper branch of $\mathrm{SC}$ is coordinates $(4.9,4.2)$, and the lower branch is coordinates $(4.9,3.0)$.

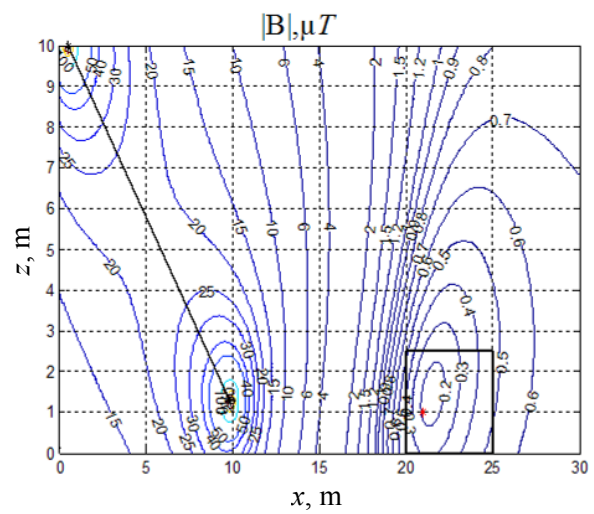

$a$

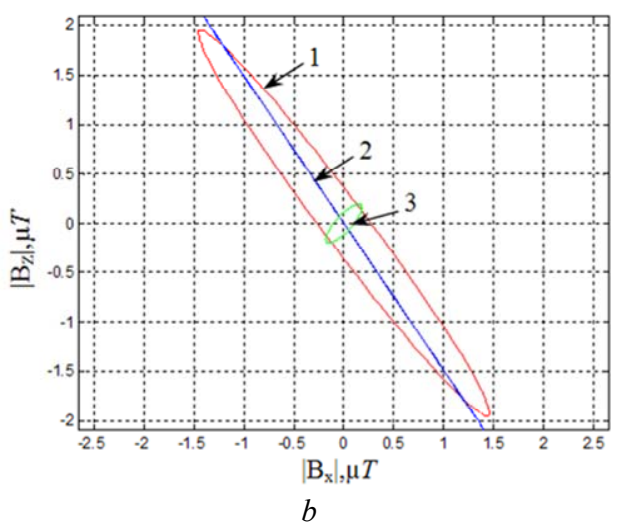

Fig. 2. Isolines of resultant magnetic flux density with the active screening system is on $(a)$ and space-time characteristics of magnetic field: initial (1), shielding coil (2) and resultant magnetic field with the system of active shielding is on (3) (b) in a two-story cottage

Fig. 3, $a$ shows the isolines of the resultant magnetic flux density with the SAS is on in the variant $(a)$. As can be seen from Fig. 3,a, the minimum magnetic flux density value in the screening zone is $0.2 \mu \mathrm{T}$. The initial MF generated by the HVPL group in the shielding zone exceeds the level of $1 \mu \mathrm{T}$ and, therefore, the maximum shielding factor of the ASS equals 5 . 
In Fig. 3, $b$ shows STC of MF, generated by: 1 - group of overhead HVPL (1); SC (2) and total MF with the SAS is on (3) at the point with the coordinates $(8.0,1.0)$.

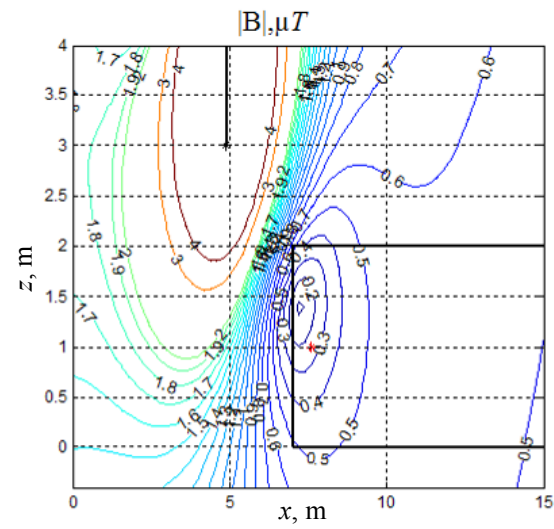

$a$

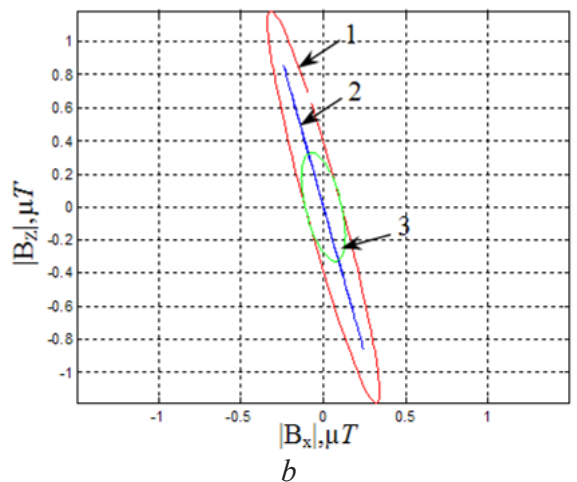

Fig. 3. Isolines of resultant magnetic flux density with the system of active screening is on $(a)$ and space-time characteristics of magnetic field: initial (1), shielding coil (2) and resultant magnetic field with the system of active shielding is on (3) $(b)$ in a single-story cottage

Let us consider the results of the synthesis of a MF SAS in a single-story building located at a same distance of $7 \mathrm{~m}$ from HVPL for the variant $(b)$. The upper branch of SC is coordinates $(5.0,0.6)$, and the lower branch is coordinates $(2.0,0.0)$.

Fig. 4,a shows the isolines of the resultant magnetic flux density with the SAS is on in the variant $(b)$. As can be seen from Fig. 4, $a$, the minimum magnetic flux density value in the screening zone also as for variant $(a)$ is 0.2 $\mu \mathrm{T}$ and, therefore, the maximum shielding factor of the ASS also as for variant $(a)$ is 5 .

In Fig. $4, b$ shows STC of MF, generated by: $1-$ group of overhead HVPL (1); SC (2) and total MF with the SAS is on (3) at the point with the coordinates $(8.0$, 1.0) also as for variant $(a)$.

Let us consider the results of the synthesis of a MF SAS for the variant $(c)$. The upper branch of SC is coordinates $(1.0,3.0)$, and the lower branch is coordinates $(4.0,1.5)$. Fig. 5, $a$ shows the isolines of the resultant magnetic flux density with the SAS is on in the variant (c). As can be seen from Fig. 5,a, the minimum magnetic flux density value in the screening zone also as for variant $(a)$ and variant $(b)$ is $0.2 \mu \mathrm{T}$ and, therefore, the shielding factor maximum of the SAS also as for variant $(a)$ and variant $(b)$ is 5. In Fig. 4, $b$ shows STC of MF, created by: 1 - group of overhead HVPL (1); SC (2) and total MF with the SAS is on (3) at the point with the coordinates $(8.0,1.0)$ also as for variant $(a)$ and variant $(b)$.

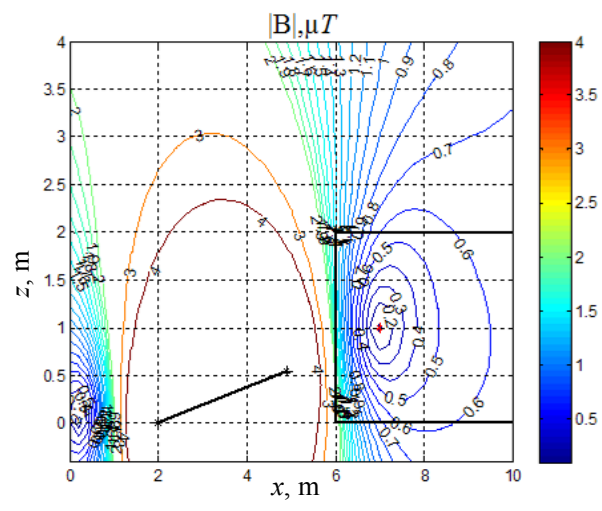

$a$

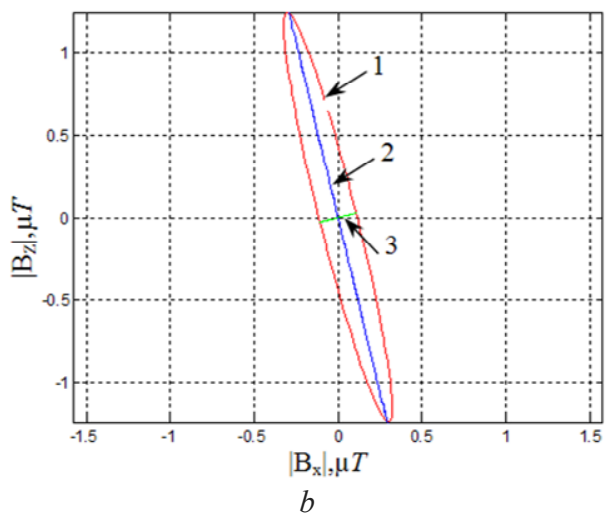

Fig. 4. Isolines of resultant magnetic flux density with the active shielding system is on $(a)$ and space-time characteristics of

magnetic field: initial (1), shielding coil (2) and resultant magnetic flux density with the systems of active shielding is on (3) $(b)$ in a single-story cottage

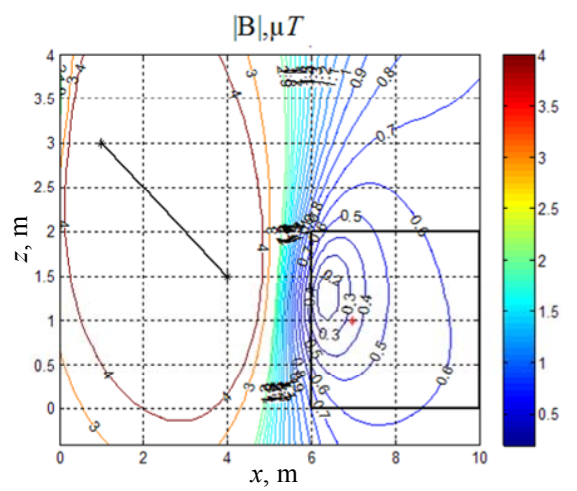

$a$

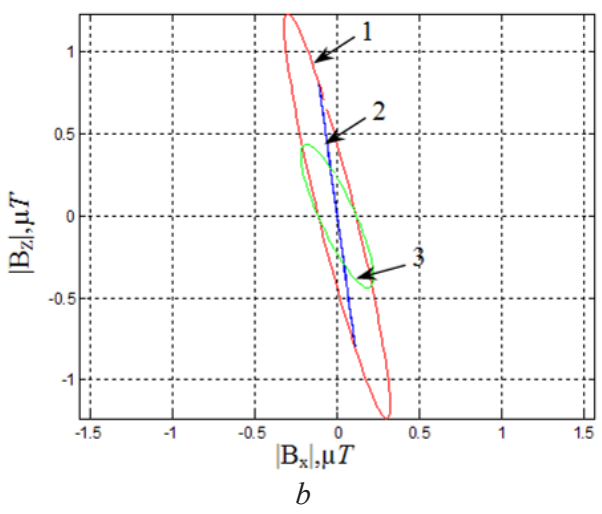

Fig. 5. Isolines of resultant magnetic flux density with the active shielding system is on $(a)$ and space-time characteristics of magnetic flux density: initial (1), shielding coil (2) and resultant magnetic flux density with the systems of active shielding is on (3) (b) in a single-story cottage 
Despite the fact that in all three variants the minimum magnetic flux density value in the screening zone also is $0.2 \mu \mathrm{T}$, however, in variant $(a)$, the magnetic flux density does not exceed the level of sanitary norms of $0.5 \mu \mathrm{T}$ in a zone of $6 \mathrm{~m}$ up to $15 \mathrm{~m}$., and in the variant $(b)$ and $(c)$, this shielding zone decreases to $8-9 \mathrm{~m}$. Thus, from the point of view of providing the greatest shielding zone of the MF, the most preferable is variant $(a)$. And from the point of view of the simplicity of SC implementing, the most preferable, apparently, is variant $(b)$.

Naturally, the STC of the initial MF at this point has the same form (curve 1). However, the position of the STC $\mathrm{MF}$ of $\mathrm{SC}$ and the resultant MF for the three options considered are somewhat different. In particular, the initial $\mathrm{MF}$ at the point under consideration is most strongly shielded in variant $(a)$.

Experimental research. Consider the field experimental research of the full scale SAS layout with three variants of SC spatial arrangement. All SC of the full scale SAS layout is a square shape, contains 20 winds and is powered by amplifier type TDA7294. The SAS contains an external Magnetic Flux Density controller and an internal current controller. An inductive sensor is used as an Magnetic Flux Density sensor, and the MF measurement is performed by EMF-828 type magnetometer of the Lutron firm [49]. The SAS is powered by an autonomous source.

Figure 6,a shows a picture of the position of $\mathrm{SC}$ of SAS for the variant $(a)$. The upper branch of SC is located at a height of $4.0 \mathrm{~m}$ from the ground, and the lower branch is located at a height of $2.6 \mathrm{~m}$ from the ground. Fig. 6, $a$ shows the experimental isolines of the resultant magnetic flux density with the SAS is on in the variant $(a)$. As can be seen from Fig. 6,a, the minimum magnetic flux density experimental value in the screening zone is $0.2 \mu \mathrm{T}$. The initial MF generated by the HVPL group in the shielding zone exceeds the level of $1 \mu \mathrm{T}$ and, therefore, the maximum experimental shielding factor of the SAS is 5 .

Figure 7, $a$ shows a picture of the spatial arrangement of SC of SAS for the variant (b). The upper branch of SC is located at a height of $0.5 \mathrm{~m}$ from the ground, and the lower branch is located at and the lower branch is located on the ground.

Figure $7, b$ shows the experimental isolines of the resultant magnetic flux density with the SAS is on in the variant $(a)$. As can be seen from Fig. 7,b, the minimum magnetic flux density experimental value in the screening zone also as for variant $(a)$ is $0.2 \mu \mathrm{T}$, and, therefore, the maximum experimental shielding factor of the SAS for the variant $(b)$ also as for variant $(a)$ equals 5 .

Figure 8, $a$ shows a picture of the spatial arrangement of SC of SAS for the variant (c). The upper branch of SC is located at a height of $3.0 \mathrm{~m}$ from the ground, and the lower branch is located at a height of $1.5 \mathrm{~m}$ from the ground. Fig. 8, $b$ shows the experimental isolines of the resultant magnetic flux density with the ASS is on in the variant $(c)$. As can be seen from Fig. 8,b, the minimum magnetic flux density experimental value in the screening zone also as for variant $(a)$ and for variant $(b)$ is $0.2 \mu \mathrm{T}$, and, therefore, the maximum experimental efficiency of the SAS for the variant $(c)$ also as for variant $(a)$ and for variant $(b)$ is 5 .

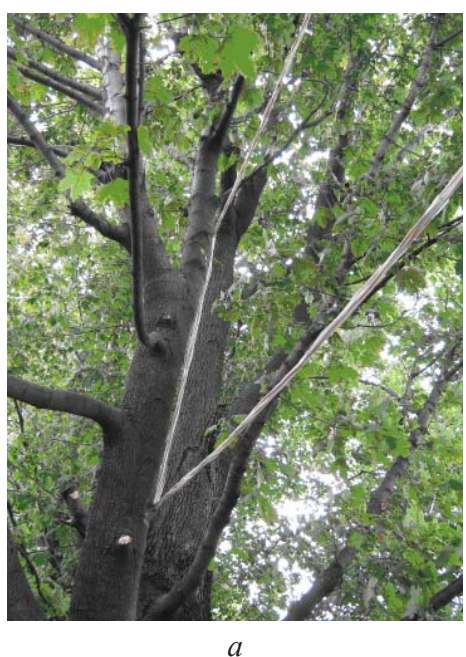

$a$

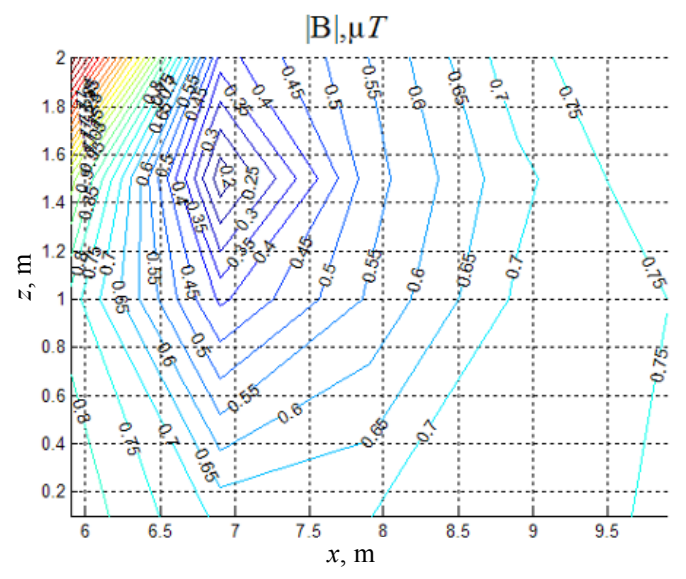

$b$

Fig. 6. Picture of the shielding coil $(a)$ and the experimental isolines of the resultant magnetic flux density with the systems of active shielding is on $(b)$

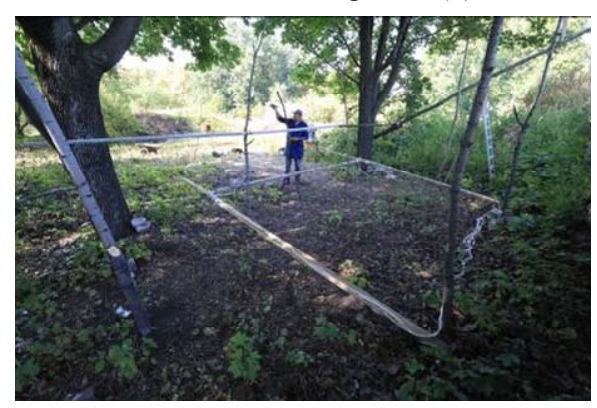

$a$

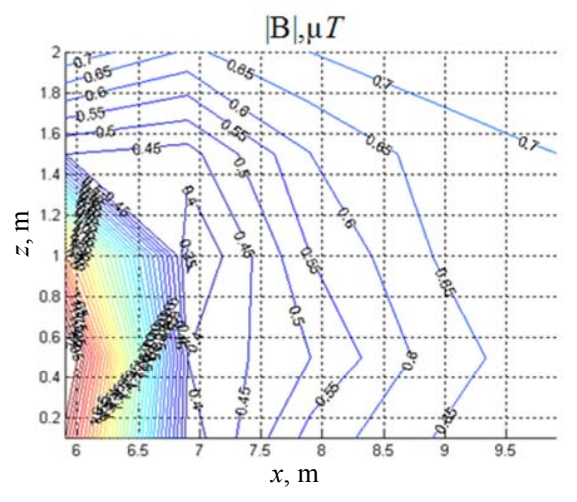

$b$

Fig. 7. Picture of the shielding coil ( $a$ ) and the experimental isolines of the resultant magnetic flux density with the systems of active shielding is on $(b)$ 


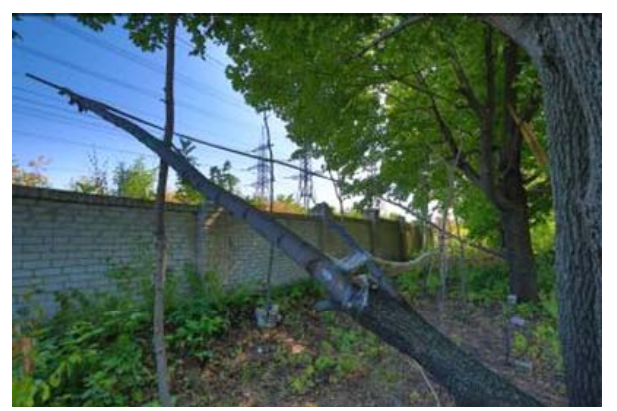

$a$

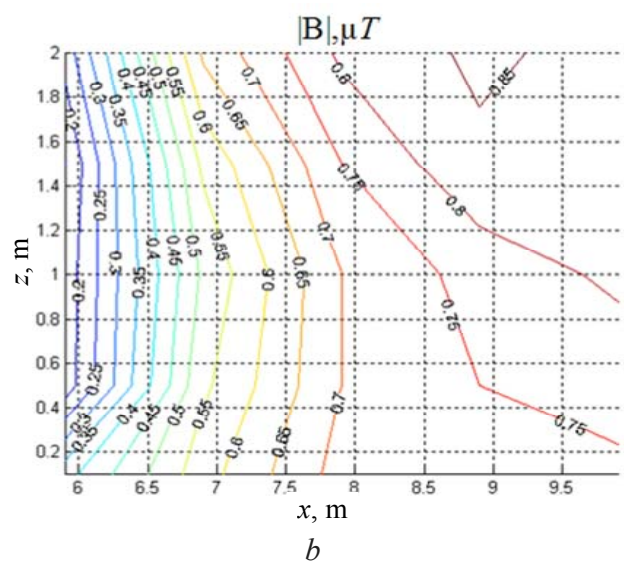

Fig. 8. Picture of the shielding coil ( $a$ ) and the experimental isolines of the resultant magnetic flux density with the systems of active shielding is on $(b)$

A comparison of the results of the MF distribution of the synthesized ASS which shown in Fig. 3,a, Fig. 5, $a$ with the experimental distributions of the SAS, which shown in Fig. 6, $b$, showed that they differ by not more than $20 \%$.

In conclusion, we note that, of course, it would be tempting not to solve the rather difficult task of synthesizing the SAS in the form of a multi-criteria game (2), but to immediately place the SC in a convenient place, in terms of simplicity of practical implementation, and experimentally adjust the SAS controls. The authors have tried to implement this option SAS, whose spatial location of SC was intuitively chosen. The upper branch of SC has coordinates $(4.9,4.2)$, and the lower branch has coordinates $(6.9,0.0)$. A spatial arrangement of such SC is shown in Fig. 9. The upper branch SC is located at a height of $4.2 \mathrm{~m}$ from the ground, and the lower branch is located at ground level.

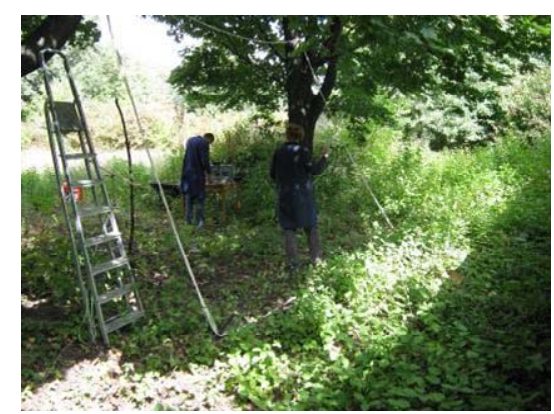

Fig. 9. Picture of the shielding coil, the spatial arrangement of which were chosen without system synthesis

However, with this SC, it was not possible to adjust the SAS regulators with the desired efficiency. Then they changed the position of the lower branch of the SC, so that the coordinates of which were equal $(4.9,0.0),(2.9$, $0.0)$ and $(4.9,1.0)$. However, it is also not possible to obtain a demand for efficiency with such a spatial arrangement of SC. Then the SAS was synthesized, the spatial position of the SC was determined, and the upper branch of the SC was set at a height of $3 \mathrm{~m}$, which corresponds to variant $(a)$. The spatial arrangement of such a SC is shown in Fig. 6,a. With this SC it was possible to get the shielding factor of the SAS more than five units.

In conclusion, we note that using single-circuit SAS containing single $\mathrm{SC}$ can effectively screen a MF with a small polarization. The STC of such MF is a very elongated ellipse whose ellipse coefficient (ratio of the smaller semiaxis to the larger half-axis) is seeks to zero. SC of single-circuit SAS generates MF, whose STC is a straight line. With such a single-circuit SAS with single $\mathrm{SC}$, the major axis of the STS ellipse of the initial MF is compensated, so that the STS of the total MF with ASS is on is significantly smaller than the STS of the initial MF, which determines the high efficiency of such singlecircuit SAS. Single-circuit power lines with horizontal and vertical bus arrangement, double-circuit power lines such as «barrel», «tree» and «inverted tree» generate a MF with a weak polarization. Exactly for such power lines, single-circuit SAS with single SC is most widely used in world practice [2].

The most polarized MF generated by a single-circuit power line with «triangle» type current conductors arrangement. The STC of such a MF is practically a circle. Therefore, for effective screening of such MF it is necessary to have two SC at least [5].

\section{Conclusions.}

1. For the first time the synthesis of robust singlecircuit systems of active shielding of magnetic field, generated by group of high voltage power lines, with different spatial arrangement of the single shielding coil carried out.

2. The synthesis of robust systems of active shielding is based on multi-criteria game decision, which is based on multiswarm stochastic multi-agent optimization from Pareto-optimal solutions.

3. As a result of the synthesis of a single-circuit systems of active shielding, three variants of the spatial arrangement of the shielding coil were selected, which are of the greatest interest from the point of view of the practical implementation.

4. Field experimental research of the effectiveness of single-circuit systems of active shielding of magnetic field generated by group of overhead high voltage power lines for three variants of the spatial arrangement of the shielding coil carried out. The shielding factor of system of active shielding equals more than 4 units. Comparison of the results of experimental and calculated values of magnetic flux density in the shielding zone shows that their spread does not exceed $20 \%$.

5. System reduce the level of the initial magnetic flux density throughout the considered residential area up to the Ukraine sanitary norms level and has less sensitivity to plant parameters variations in comparison with the known systems. 


\section{REFERENCES}

1. Rozov V.Yu., Reutskyi S.Yu., Pelevin D.Ye., Pyliugina $\mathrm{O} . \mathrm{Yu}$. The magnetic field of transmission lines and the methods of its mitigation to a safe level. Technical Electrodynamics, 2013, no. 2, pp. 3-9. (Rus).

2. Active Magnetic Shielding (Field Cancellation). Available at: http://www.emfservices.com/afcs.html (accessed 10 September 2012).

3. Ter Brake H.J.M., Huonker R., Rogalla H. New results in active noise compensation for magnetically shielded rooms. Measurement Science and Technology, 1993, Vol. 4, Issue 12, pp. 1370-1375. doi: 10.1088/0957-0233/4/12/010.

4. Celozzi S., Garzia F. Active shielding for power-frequency magnetic field reduction using genetic algorithms optimization. IEE Proceedings - Science, Measurement and Technology, 2004, Vol.151, no.1, pp. 2-7. doi: 10.1049/ip-smt:20040002.

5. Shenkman A., Sonkin N., Kamensky V. Active protection from electromagnetic field hazards of a high voltage power line. HAIT Journal of Science and Engineering. Series B: Applied Sciences and Engineering, Vol. 2, Issues 1-2, pp. 254-265.

6. Beltran H., Fuster V., García M. Magnetic field reduction screening system for a magnetic field source used in industrial applications. 9 Congreso Hispano Luso de Ingeniería Eléctrica (9 CHLIE), Marbella (Málaga, Spain), 2005, pp. 84-99.

7. Rozov V.Yu., Grinchenko V.S., Pelevin D.Ye., Chunikhin K.V. Simulation of electromagnetic field in residential buildings located near overhead lines. Technical electrodynamics, 2016, no.3, pp. 6-8. (Rus).

8. Bravo-Rodríguez J., Del-Pino-López J., Cruz-Romero P. A Survey on Optimization Techniques Applied to Magnetic Field Mitigation in Power Systems. Energies, 2019, vol.12, no.7, p. 1332. doi: 10.3390/en12071332.

9. Celozzi S. Active compensation and partial shields for the power-frequency magnetic field reduction. IEEE International Symposium on Electromagnetic Compatibility. Minneapolis, USA, 2002, pp. 222-226. doi: 10.1109/isemc.2002.1032478.

10. Celozzi S., Garzia F. Magnetic field reduction by means of active shielding techniques. Environmental Health Risk II, 8 September, 2003, pp. 64-73. doi: 10.2495/ehr030091.

11. The World Health Organization. The International EMF Project. [Online]. Available at: http://www.who.int/pehemf/project/en/. (accessed 17 February 2017).

12. Electrical installation regulations. 5 th ed. The Ministry of Energy and Coal Mining of Ukraine, 2014. 277 p. (Ukr).

13. Cruz Romero P., Izquierdo Mitchell C., Burgos Payan, M. Optimal split-phase configurations. In Proceedings of the 2001 IEEE Porto Power Tech Proceedings (Cat. No.01EX502), Porto, Portugal, 10-13 September 2001, vol.3, p. 5.

14. Cruz Romero P., Izquierdo C., Burgos M., Ferrer L.F., Soto F., Llanos C., Pacheco J.D. Magnetic field mitigation in power lines with passive and active loops. In Proceedings of the CIGRE Session, Paris, France, 25-30 August 2002.

15. Barsali S., Giglioli R., Poli D. Active shielding of overhead line magnetic field: Design and applications. Electric Power Systems Research, 2014, vol.110, pp. 55-63. doi: 10.1016/j.epsr.2014.01.005.

16. Del Pino Lopez J.C., Romero P.C. Influence of Different Types of Magnetic Shields on the Thermal Behavior and Ampacity of Underground Power Cables. IEEE Transactions on Power Delivery, 2011, vol.26, no.4, pp. 2659-2667. doi: 10.1109/tpwrd.2011.2158593.

17. Del Pino-Lopez J.C., Cruz-Romero P., SerranoIribarnegaray L. Impact of electromagnetic losses in closed twocomponent magnetic shields on the ampacity of underground power cables. Progress in electromagnetics research, 2013, vol.135, pp. 601-625. doi: 10.2528/pier12112303.

18. del-Pino-López J.C., Giaccone L., Canova A., Cruz-Romero P. Design of active loops for magnetic field mitigation in
MV/LV substation surroundings. Electric Power Systems Research, 2015, vol.119, pp. 337-344. doi: 10.1016/j.epsr.2014.10.019.

19. del Pino Lopez J.C., Giaccone L., Canova A., Cruz Romero P. Ga-based active loop optimization for magnetic field mitigation of $\mathrm{MV} / \mathrm{LV}$ substations. IEEE Latin America Transactions, 2014, vol.12, no.6, pp. 1055-1061. doi: 10.1109/tla.2014.6894000.

20. Canova A., Giaccone L. Real-time optimization of active loops for the magnetic field minimization. International Journal of Applied Electromagnetics and Mechanics, 2018, vol.56, pp. 97-106. doi: 10.3233/jae-172286.

21. Canova A., del-Pino-Lopez J.C., Giaccone L., Manca M. Active Shielding System for ELF Magnetic Fields. IEEE Transactions on Magnetics, 2015, vol.51, no.3, pp. 1-4. doi: 10.1109/tmag.2014.2354515.

22. Femia N., Petrone G., Spagnuolo G., Vitelli M. Optimization of Perturb and Observe Maximum Power Point Tracking Method. IEEE Transactions on Power Electronics, 2005, vol.20, no.4, pp. 963-973. doi: 10.1109/tpel.2005.850975. 23. Kuznetsov B.I., Turenko A.N., Nikitina T.B., Voloshko A.V., Kolomiets V.V. Method of synthesis of closed-loop systems of active shielding magnetic field of power transmission lines. Technical electrodynamics, 2016, no.4, pp. 8-10. (Rus).

24. Kuznetsov B.I., Nikitina T.B., Voloshko A.V., Bovdyj I.V., Vinichenko E.V., Kobilyanskiy B.B.. Synthesis of an active shielding system of the magnetic field of power lines based on multiobjective optimization. Electrical engineering \& electromechanics, 2016, no.6, pp. 26-30. (Rus). doi: 10.20998/2074-272X.2016.6.05.

25. Ren Z., Pham M.-T., Koh C.S. Robust Global Optimization of Electromagnetic Devices With Uncertain Design Parameters: Comparison of the Worst Case Optimization Methods and Multiobjective Optimization Approach Using Gradient Index. IEEE Transactions on Magnetics, 2013, vol.49, no.2, pp. 851859. doi: 10.1109/tmag.2012.2212713.

26. Ranković A. Novel multi-objective optimization method of electric and magnetic field emissions from double-circuit overhead power line. International Transactions on Electrical Energy Systems, 2016, vol.27, no.2, p. e2243 doi: 10.1002/etep.2243.

27. Ummels M. Stochastic Multiplayer Games Theory and Algorithms. Amsterdam University Press, 2010. 174 p.

28. Rozov V.Yu., Reutskyi S.Yu. Pyliugina O.Yu. The method of calculation of the magnetic field of three-phase power lines. Technical electrodynamics, 2014, no.5, pp. 11-13. (Rus).

29. Panchenko V.V., Maslii A.S., Pomazan D.P., Buriakovskyi S.G. Determination of pulsation factors of the system of suppression of interfering harmonics of a semiconductor converter. Electrical engineering \& electromechanics, 2018, no.4, pp. 24-28. doi: 10.20998/2074-272X.2018.4.04.

30. Buriakovskyi S., Maslii A., Maslii A. Determining parameters of electric drive of a sleeper-type turnout based on electromagnet and linear inductor electric motor. Eastern-European Journal of Enterprise Technologies, 2016, vol.4, no.1(82), pp. 32-41. (Rus). doi: 10.15587/1729-4061.2016.75860.

31. Zagirnyak M., Chornyi O., Nykyforov V., Sakun O., Panchenko K. Experimental research of electromechanical and biological systems compatibility. Przeglad Elektrotechniczny, 2016, vol.1, no.1, pp. 130-133. doi: 10.15199/48.2016.01.31.

32. Buriakovskyi S.G., Maslii A.S., Panchenko V.V., Pomazan D.P., Denis I.V. The research of the operation modes of the diesel locomotive CHME3 on the imitation model. Electrical engineering \& electromechanics, 2018, no.2, pp. 59-62. doi: 10.20998/2074-272X.2018.2.10.

33. Rozov V., Grinchenko V. Simulation and analysis of power frequency electromagnetic field in buildings closed to overhead lines. 2017 IEEE First Ukraine Conference on Electrical and 
Computer Engineering (UKRCON). Kyiv, Ukraine, pp. 500-503. doi: $10.1109 /$ UKRCON.2017.8100538.

34. Zagirnyak M., Serhiienko S., Chornyi O. Innovative technologies in laboratory workshop for students of technical specialties. 2017 IEEE First Ukraine Conference on Electrical and Computer Engineering (UKRCON), May 2017. doi: 10.1109/ukrcon.2017.8100446.

35. Chystiakov P., Chornyi O., Zhautikov B., Sivyakova G. Remote control of electromechanical systems based on computer simulators. 2017 International Conference on Modern Electrical and Energy Systems (MEES), Nov. 2017. doi: 10.1109/mees.2017.8248934.

36. Korol S., Buryan S., Pushkar M., Ostroverkhov M. Investigation the maximal values of flux and stator current of autonomous induction generator. 2017 IEEE First Ukraine Conference on Electrical and Computer Engineering (UKRCON), May 2017. doi: 10.1109/ukrcon.2017.8100302.

37. Galchenko V.Y., Yakimov A.N. A turmitobionic method for the solution of magnetic defectometry problems in structuralparametric optimization formulation. Russian Journal of Nondestructive Testing, 2014, vol.50, no.2, pp. 59-71. doi: 10.1134/s106183091402003x.

38. Clerc M. Particle Swarm Optimization. London, ISTE Ltd., 2006. 244 p. doi: 10.1002/9780470612163.

39. Shoham Y., Leyton-Brown K. Multiagent Systems: Algorithmic, Game-Theoretic, and Logical Foundations. Cambridge University Press, 2009. 504 p.

40. Xiaohui Hu, Eberhart R.C., Yuhui Shi. Particle swarm with extended memory for multiobjective optimization. Proceedings of the 2003 IEEE Swarm Intelligence Symposium. SIS'03 (Cat. No.03EX706). doi: 10.1109/sis.2003.1202267.

41. Michalewicz Z., Schoenauer M. Evolutionary Algorithms for Constrained Parameter Optimization Problems. Evolutionary Computation, 1996, vol.4, no.1, pp. 1-32. doi: 10.1162/evco.1996.4.1.1.

42. Parsopoulos K.E., Vrahatis, M.N. Particle Swarm Optimization Method for Constrained Optimization Problems. In Proceedings of the Euro-International Symposium on Computational Intelligence, 2002, pp. 174-181.

43. Pulido G.T., Coello C.A.C. A constraint-handling mechanism for particle swarm optimization. Proceedings of the 2004 Congress on Evolutionary Computation (IEEE Cat. No.04TH8753). doi: 10.1109/cec.2004.1331060.
44. Ray T., Liew K.M. A Swarm Metaphor for Multiobjective Design Optimization. Engineering Optimization, 2002, vol.34, no.2, pp. 141-153. doi: 10.1080/03052150210915.

45. Coello Coello C.A, Reyes-Sierra M. Multi-Objective Particle Swarm Optimizers: A Survey of the State-of-the-Art. International Journal of Computational Intelligence Research, 2006, vol.2, no.3, pp. 287-308. doi: 10.5019/j.ijcir.2006.68.

46. De Freitas Vaz A.I., Da G. Pinto Fernandes E.M. Optimization of nonlinear constrained particle swarm. Technological and Economic Development of Economy, 2006, vol.12, no.1, pp. 30-36. doi: 10.3846/13928619.2006.9637719.

47. Zilzter Eckart. Evolutionary algorithms for multiobjective optimizations: methods and applications. Ph. D. Thesis Swiss Federal Institute of Technology. Zurich, 1999. $114 \mathrm{p}$.

48. Xin-She Yang, Zhihua Cui, Renbin Xiao, Amir Hossein Gandomi, Mehmet Karamanoglu. Swarm Intelligence and BioInspired Computation: Theory and Applications, Elsevier Inc., 2013. $450 \mathrm{p}$

49. Kuznetsov B.I., Nikitina T.B., Voloshko A.V., Bovdyj I.V., Vinichenko E.V., Kobilyanskiy B.B. Experimental research of magnetic field sensors spatial arrangement influence on efficiency of closed loop of active screening system of magnetic field of power line. Electrical engineering \& electromechanics, 2017, no.1, pp. 16-20. doi: 10.20998/2074-272X.2017.1.03.

Received 23.04.2019

B.I. Kuznetsov ${ }^{1}$, Doctor of Technical Science, Professor,

T.B. Nikitina ${ }^{2}$, Doctor of Technical Science, Professor,

I.V. Bovdui ${ }^{1}$, Candidate of Technical Science,

${ }^{1}$ State Institution «Institute of Technical Problems of Magnetism of the NAS of Ukraine»,

19, Industrialna Str., Kharkiv, 61106, Ukraine, phone +380 505766900 ,

e-mail: kuznetsov.boris.i@gmail.com

${ }^{2}$ Kharkov National Automobile and Highway University, 25, Yaroslava Mudroho Str., Kharkov, 61002, Ukraine, e-mail: tatjana55555@gmail.com

\section{How to cite this article:}

Kuznetsov B.I., Nikitina T.B., Bovdui I.V. High voltage power lines magnetic field system of active shielding with compensation coil different spatial arrangement. Electrical engineering \& electromechanics, 2019, no.4, pp. 17-25. doi: 10.20998/2074-272X.2019.4.03. 